\title{
Growth in Motivation, Performance, and Positive Emotions: Experiential Learning in Macro Social Work
}

ANDREA SILVERMAN, MSW, LSW ${ }^{1}$; MORGAN FRIEDMAN, MSW ${ }^{1}$; JALISA WHITINGSMALLS, MSCJ, MSW, LSW ${ }^{1}$; NADI DAMOND WISSEH, MSW, LSW ${ }^{1}$; LAURIE FRIEDMAN, PHD, LCSW, MPA; JENNIFER IBRAHIM, PHD, $\mathrm{MPH}^{2}$

${ }^{1}$ School of Social Work, College of Public Health, Temple University

${ }^{2}$ Department of Health Services Administration and Policy, College of Public Health, Temple University

Correspondence: andemichele07@gmail.com (Andrea Silverman)

The Control V alue Leaning Theory can be used to understand and impact student knowledge, interest, and experiences in content relating to bealth professions and associated topics, including working with organizations and communities and being a part of a task group or interdisciplinary team. This case study reports on the experiences of 19 students in a graduate practice social work course: Practice of Social Service Delivery II. Students' increased control and input in assignments and perception of the assignments' value were associated with increased motivation, performance, and enjoyment. Experiential learning opportunities that emphasized greater student choice and value increased students' exposure to the professional realm and appeared to increase the perceived importance of a course topic in which students previously bad low knowledge and interest.

\section{Introduction}

Social Work programs require courses that teach skills needed to work with individuals, families, groups, organizations, and communities. ${ }^{1}$ Macro Social Work skills - including working with communities and organizations, developing policies, and administrative and leadership work - are essential for social workers and can also be generalized across many practice-based disciples, including public health, nursing, and speech. The importance of these skills is incorporated into the first year of the program to ensure all students, regardless of their advanced year curriculum focus, acquire skills in these areas.

\section{Experiential Learning}

Experiential learning is an active process that integrates academic and professional learning through firsthand experiences in the classroom and/or in communities. ${ }^{2,3}$ It provides students with multiple benefits, including increased self-awareness, increased appreciation for individual clients and neighborhoods, and meaningful skills that can be used in future situations. ${ }^{2,4}$ Prior research demonstrates the value of experiential learning across disciplines, such as in social work clinical and macro practice 
courses. ${ }^{5-8}$ Timm and colleagues highlight that "the internalization and ownership of knowledge gained through experiential, active learning allow the learning to be meaningful and long-lasting, and ultimately to assist in promoting effective social work practice". ${ }^{2}$ Experiential learning also facilitates students' abilities to work in task groups, increase their confidence and appreciation of responsibility, ${ }^{9-10}$ and develop their communication and organizational skills. These experiences provide students with the chance to actively control and engage with valuable learning opportunities, which ultimately enhances a variety of educational components.

\section{Control Value Learning Theory}

The Control Value Learning Theory posits that student motivation, performance, and emotions toward tasks are associated with the amount of control they have and the value they place on activities and outcomes. ${ }^{11}$ Undergraduate and graduate students juggle multiple responsibilities: required coursework, fieldwork, and personal life commitments. ${ }^{12}$ Because students' responsibilities require their constant attention, instructors need to intentionally engage and motivate students in their learning. This is especially important when the content is required but may not be the primary interest of students. This theory provides additional context to understand why experiential learning is effective and builds upon experiential learning to provide a framework for instructors to consider when designing their courses.

Experiential learning opportunities give students a degree of control in how they want to engage with and what they want to gain from the experience. When students are allowed to have input in assignments and link them to their personal and professional lives and interests, there is an increased sense of interest, enthusiasm, and empowerment. ${ }^{5,13}$ Furthermore, students appear to learn better when they enjoy what they are doing. ${ }^{2}$ Control Value Theory also emphasizes the importance of the perceived value of tasks. ${ }^{11}$ Students in practice-based disciplines, including social work and other health professions, have reported that they prefer when faculty make the course relevant to real-world applications by incorporating knowledge and examples from the field or work experience. ${ }^{14,15,16}$ When faculty provide students with material that both meets interests and is challenging, students will benefit both in their interest and ability. ${ }^{11}$ Hands-on experiential learning opportunities can therefore be used to peak student interest and enhance students' perception of the applicability of course activities to their professional goals. ${ }^{2,4}$

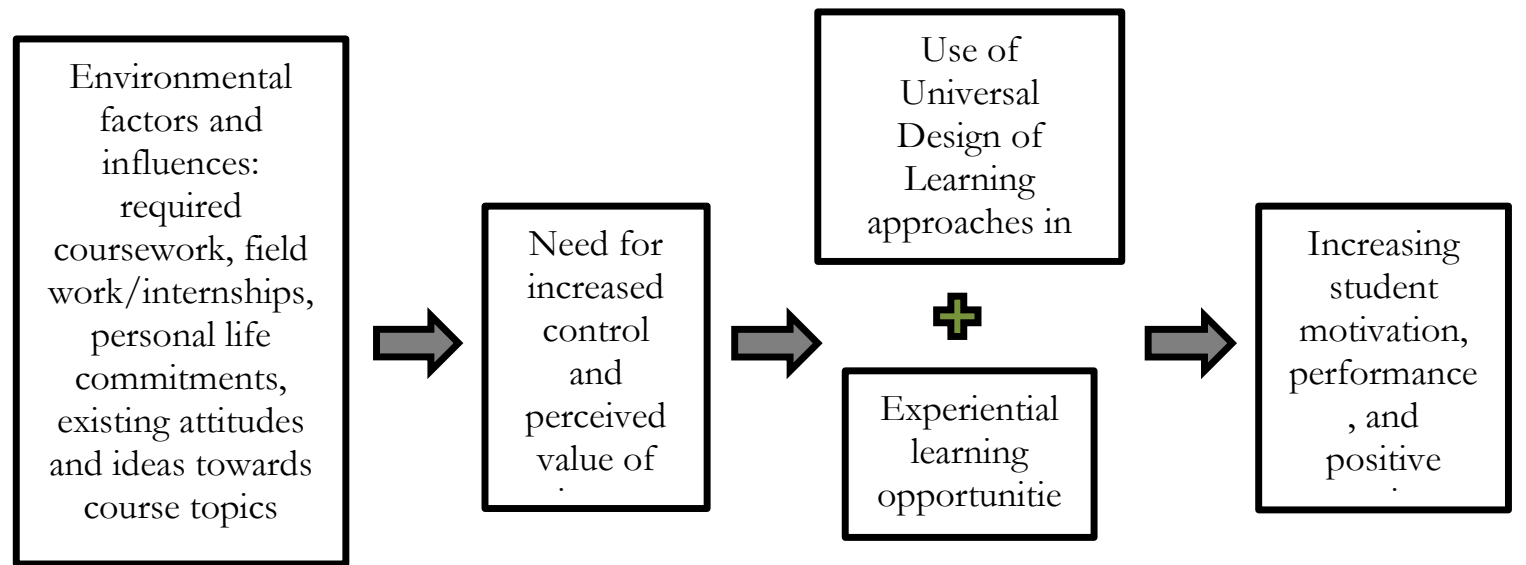

Figure 1. Impact of Control Value Theory and Experiential Learning ${ }^{11,17}$

Control Value Theory also aligns with Universal Design of Learning (UDL) ${ }^{17}$, which recognizes that students have different learning preferences. Instructors who integrate UDL principles in their courses embed opportunities for students to choose how they will engage with the content and how they will 
demonstrate what they learned. Students report that UDL strategies, including providing multiple means of representation of an assignment and providing multiple means of engagement, lead to higher satisfaction and engagement and more positive attitudes. ${ }^{17}$ An example of using UDL in this case example is providing students with the choice to interview community members or conduct research about the community. Both options require students to learn about and interact with the community but invites them to choose how they want to engage. Allowing for more student choice creates opportunities for students to learn in the ways most successful for them and ultimately place more value onto the material.

Research on control-value theory also conveys the importance of emotions in student engagement and motivation. ${ }^{11}$ Different combinations of students' perceived control and the perceived value of an activity result in four distinct emotions: enjoyment, anger, frustration, and boredom. Enjoyment was found in students who had high perceived control and value and was positively related to their motivation. Negative emotions, including boredom and frustration, were found in students who experienced no kind of value and no amount of control, respectively. ${ }^{11,18}$ Additionally, an instructor's enthusiasm about a task can influence the students' enthusiasm and individual students' emotions can be contagious in the classroom. 19,20,11 Encouragement of student input has been shown to lead to higher enthusiasm and enjoyment, both in how students complete their assignments and participation in the task groups.5,21 The literature ultimately suggests that greater student control of their assignments and class activities along with the higher perceived value of these activities can help ensure required course goals are met and skills are learned as well as increase student enjoyment of the class.

This case report demonstrates the connection between experiential learning and Control Value Learning Theory using a course-based learning assignment. By further incorporating the student perspective into experiential learning, there is potential for higher-impact student learning.

\section{Case Study}

\section{Course Description}

The goals of this particular course include working in interdisciplinary teams, using evidence-based practice and active listening skills when working with organizations and communities. Throughout the course, Control Value Theory expanded on experiential learning to help frame the design of the assignments and class activities, helping to explain the process through which students engaged in the course and left with increased knowledge of the subject and increased preparation for the workforce.

\section{Adaptation and Implementation of Course Assignments}

To prepare for the course, the instructor followed up with members of a local community organization with which they had a prior relationship to lay out a tentative plan for how the assignments could meet both the course goals and contribute to the organization's goals. During the second week of the course, the students and members of the organization met with each other to introduce everyone and begin the working relationship.

After the initial community visit, students completed three assignments throughout the course of the semester. The first two were completed in groups and the third was completed individually.

- A geographic community assessment

- A community intervention project.

- Organizational change analysis or analysis of trauma informed practices 
The community assessment included five task groups (with students choosing which one to participate in) and they produced a comprehensive community assessment, consisting of 15 different topic areas including multiple sources of information. The community intervention assignment comprised of seven smaller task groups, each with 2-4 student members (again with students providing input into their desired group). The main goal of the first half of the course was to assess the community as a whole, focusing specifically on its strengths and what the community members identified as target areas they wanted to improve. This was conducted through traditional research of existing information and direct interviews with community members. The ideas for assignments and final intervention proposal began with the initial community visit and stemmed from each component of the class assignment.

In the second half of the course, students collectively chose what the intervention would be based on the information gathered in the community assessment. Students specifically used community member feedback as a guide, both from information gathered in the class community visit and from interviews conducted with community members and organizations. These two assignments provided students with additional concrete macro social work opportunities of assessing a community and thinking about and creating plans for larger-scale change with a community. Additionally, the opportunities to interact with individuals highlighted the importance of listening to and advocating for community members' ideas. Students even constructed a proposal for a faculty member in the field office as a potential future macro field placement, creating an individualized culmination of the assignment.

Throughout the course, the instructor assumed the role of a consultant, answering questions as they arose within the class, but students took most of the responsibilities upon themselves, including assigning task group roles, assessment sections, deadlines, and formatting guidelines and instructions. Students also facilitated class meetings and wrote meeting agendas and minutes. The instructor demonstrated how control can be somewhat like a see-saw; by providing students more choice, they took on a consultant role with less control than a typical instructor.

\begin{tabular}{ll}
$\begin{array}{ll}\text { Table } 1 . \\
\text { Community Assessment }\end{array}$ \\
\hline \multicolumn{1}{c}{ Included Sections } \\
\hline 1 & General Information \\
2 & Family Life \\
3 & Health \\
4 & Community Maintenance \\
5 & Community Spirit \\
6 & Recreation \\
7 & Transportation \\
8 & Communication \\
9 & Education \\
10 & Economy \\
11 & Production \\
12 & Religion/Spirituality \\
13 & Safety \\
14 & Politics/Public Service \\
15 & Justice \\
\hline
\end{tabular}


Table 2

Assignment Descriptions

Assignment 1

The five groups in this assignment were community research, organization research, community and organization interviews, mapping, and an editing group. The community research group researched the history and current status of various aspects of the assigned community using the internet, the library, and other sources through a general literature search. This ultimately resulted in a mix of peer-reviewed sources and other news articles and government websites. Research for the organization group focused on researching the partnering organization's history and collating associated news stories, journal articles, and movies. The third group conducted approximately five convenience interviews with community members, including those from religious institutions, local businesses, and other community groups to inform their assessment. This group augmented work by the other task groups, and then went further in their questions. The mapping group created a map highlighting the assets of the geographic community. Lastly, the editing group synthesized and analyzed the information acquired from the other task groups into a comprehensive community assessment.

\section{Assignment 2}

The groups for the intervention assignment included a variety of roles to research, develop, and present the created intervention plan. Several of the groups worked on creating the foundation for the need for intervention; one group wrote a justification statement for the selected problem and one group wrote up an Epidemiology (Incidence) \& Etiology (Cause) of the selected community problem to describe the background of the problem and how it impacted the community. Several groups focused on the details of the actual intervention development. A total of five different groups worked on the intervention's components, including a summary of contextual factors for success in the community, a menu of change alternatives, a write up of the justification for the selected intervention, documentation of the selected intervention, and an intervention logic model. Lastly, groups worked on the summation of the final document and the final intervention proposal.

\section{Assignment 3}

For the third assignment, students individually wrote a paper about an organization of their choice. Most wrote about the organization at which they worked or did their field placements at. Students were provided with two options of how to analyze their chosen organization and got to choose which they felt would be a better fit or would better serve their experience in the class. The first option, an organizational change paper, provided students with the opportunity to analyze a change effort in their organization and describe what led to the change, how it happened, who was involved, and the resulting impacts. The second option provided students with the opportunity to analyze their organization's use of trauma-informed practices and propose intervention strategies to improve the organizational areas of the assessment. The assessment included five key areas of assessment, including Supporting Staff Development, Creating a Safe and Supportive Environment, Assessing and Planning Services, Involving Consumers, and Adapting Policies.

The course consisted of 19 students in the university's Master of Social Work (MSW) program. Students in this section were in their first year of the program. At least $75 \%$ of the students were full-time, intending to pursue a clinical concentration, under the age of 30 , and at least $50 \%$ of the students were currently placed in social work field placements.

The instructor reviewed the two student reflection papers, in which students were asked to write about the development of their task group, how they delineated responsibilities, interactions with group members, the role of the instructor as a consultant, and personal reflections as a group member. The instructor created a summary of key passages that spoke to students' perceptions of what they had learned from the two group assignments, ensuring the confidentiality of the responses. The student authors then collectively reviewed the data from the written reflection summaries and reviewed recordings of the class in the second half of the semester (post Covid-19 and therefore online and recordable). Through 
discussion and each author's contribution of ideas, they confirmed a series of major themes that emerged that reflected how the Control Value Theory could be used to understand the students' thoughts and experiences.

Several major themes emerged from student reflections: areas where students perceived control within the class, areas where they perceived value from the assignments and activities, and associated impacts on motivation, performance, and emotions.

\section{Perceived Control}

Students identified the importance of being able to choose their specific tasks groups, create their group norms and agendas and take initiative in their learning.

- We each voluntarily chose to be part of this team, and during our first meeting, discussed expectations, group rules and guidelines, and tasks and responsibilities. This enabled all of us to be on the same page about each of these important aspects of our work together."

- "I enjoyed being able to choose between two options for the final paper for the class."

\section{Perceived Value}

Students identified the value of working in student task groups and collaborating with the rest of the class on their ability to work with task groups in their professional lives. Students also identified that engagement with an outside organization increased their understanding of macro social work and provided them with meaningful opportunities to engage with a community.

- II think that this entire project including the assessment and intervention has taught me a lot about professionalism and working in task groups. .. tasks groups created a sense of professionalism by having detailed deadlines, goals, and consultants."

- What I have enjoyed the most about this project has been the opportunity to engage in real community participation and partnership. Before this course, I struggled to see and appreciate the value of macrolevel social work; however, this project allowed me to recognize and experience the importance of it firstband."

\section{Motivation, Performance, and Positive Emotions}

In their reflections, students also articulated that their perceived value of the course was closely associated with experiencing motivation, improved performance, and positive emotions.

Students in the course reported experiencing and enjoying increased learning and skills-building, specifically including transferable skills required to be in a task group.

- "T became more self-assured in my abilities to successfully run a task force."

- "This project has allowed me to develop and grow in my role working in groups, providing me with an example that there are more than one way to contribute to a group."

\section{Discussion}

Graduate social work students are required to learn a variety of skills about which initial student knowledge is low.22,23 Similar to many undergraduate and graduate students in other disciplines, there seems to be a lack of motivation to learn some of the key components of the required curriculums. The results of this case study suggest that such interest and knowledge can change when students gain 
concrete experience as well as increased control and perception of the value of learning opportunities. This ultimately appeared to lead to increased student motivation, performance, and enjoyment of the course. ${ }^{11,18,19}$

The first part of Control Value Theory highlights the importance of having some control or input in a task. ${ }^{11}$ In this course, students were allowed to choose their task groups based on interest. It is important to note that while students chose which group they wanted to be in, the purpose of each group was predetermined. Since students begin courses with varying degrees of knowledge, it was also important that the instructor set realistic limits to student control. ${ }^{18}$ This allowed students to have input while still receiving the necessary guidance and education from the instructor. Students had control over their learning experience by choosing which tasks best aligned with their interests and time availability. Additionally, during the intervention portion of the assignment, each student participated in determining the focus and selection of the specific intervention. By talking with community members, students were able to collaboratively identify a more salient cause for intervention. It is clear from the reflections and student statements during class that students appreciated having this opportunity for input and it led to increased excitement about the project.

The second component of the Control Value Theory's framework highlights the importance of the perceived value of a task for students. ${ }^{11}$ Amerman-Goerdt and colleagues ${ }^{14}$ found that students prefer real-world relevance in their courses. In this course, students gained real-world experience through their work interacting with the community, assessing strengths and areas in which they wanted to improve, and delineating and proposing a thorough intervention plan. Since many students in the course had expressed a greater interest in clinical social work, the initial perceived value of a class centering around macro practice was low; however, after completing the course, students expressed that they found the course to be valuable. The student authors also found the course to be more valuable than anticipated because of the professional experiences gained throughout and increased recognition of the course's importance and working with each other as members of a task group. The data collected shows that the inclusion of experiential learning gave students exposure to the professional social work realm and assignments they perceived as valuable and impactful to the community.

In addition to identified perceptions of control and value, the reflections conveyed that students had growth in motivation, performance, and positive emotions. It is clear from the collected reflections that students felt they gained a better understanding of how to effectively work in task groups and partner with communities or organizations, both of which are important tenets of macro social work practice and help students to expand their skill sets and grow in desired areas. ${ }^{22,24}$ Additionally, students described a variety of positive emotions, noting that they experienced excitement, self-assurance, and enjoyment. The findings here support prior research that student input leads to an increased sense of interest, enthusiasm, and empowerment., 513 This combination of growth in performance and experience of positive emotions appears to have helped build students' confidence and motivation for future professional experiences.

Ideally, there would have been more time devoted to this project, as relationship building with followthrough is a critical aspect of work in communities to allow the class experience to be improved. ${ }^{4}$ Due to limitations around Covid-19, the class was unable to fully collaborate with the organization to the initial planned extent. Our results section includes feedback from students' reflection papers written for the class, but only the instructor could look at these papers due to confidentiality; therefore, the instructor was the only one able to pull out quotes and highlight themes emerging from the papers. The student authors chose quotes from the instructor's selection. Finally, the Covid-19 related changes that occurred to the course also had an impact on students' experiences, including difficulties transitioning to the online 
course format and limiting expectations for connecting with the organization to discuss the intervention plan.

\section{Conclusions}

Working with diverse organizations necessitates that individuals in practice-based disciplines are able to develop collaborative relationships, assess multiple sources of information and choose priorities in their larger social context to be effective. Experiential learning has emerged as a useful strategy in helping students enjoy required first year courses that students may not be initially attracted to because students can have hands-on and active experiences. ${ }^{2,3}$ In this case study, students met the course goals and gained valuable professional opportunities through experiential learning, including partnering with organizations, engaging with a community, working in task groups, conducting a community assessment, and creating an intervention plan. Additionally, students could have input in the project and in their groups, which allowed them to target desired areas of growth.

Per the theoretical principles of the Control Value Theory, the course's experiential learning opportunities that allowed for choice and held perceived value led to positive impacts on motivation, performance, and emotions experienced. ${ }^{11}$ The presence of student control and experiential learning in the course design worked to decrease the power differential between the students and the professor and helped to facilitate a learning experience that approximated social workers' roles and increasing readiness for working in the field. These findings show that focusing on choice and value in experiential learning opportunities is an effective tool in increasing student knowledge and enjoyment of required topics.

\section{Disclosures and Conflicts of Interest}

Dr. Jennifer Ibrahim is Faculty Co-Editor of CommonHealth. The other authors have nothing to disclose.

\section{Acknowledgments}

We acknowledge and thank community partners and community members, and our peers for sharing their experiences that were used as data collection and results.

\section{References}

1. Council on Social Work Education. Educational policy and accreditation standards. 2015. Retrieved from https://www.cswe.org/Accreditation/ Standards-and-Policies/2015-EPAS.

2. Timm T, Birkenmaier J, Tebb S. The Experiential Community Assessment Project: Integrating Social Work Practice Skills. Journal of Community Practice. 2011;19(2):175-188 doi:10.1080/10705422.2011.569649.

3. Jarvis P. Adult and continuing education. Theory and practice (2nd ed.). London, UK: Routledge; 1995. 
4. Frank JM, Granruth LB, Girvin H, VanBuskirk A. Bridging the Gap Together: Utilizing Experiential Pedagogy to Teach Poverty and Empathy. Journal of Social Work Education. 2019. 1-14. doi:10.1080/10437797.2019.1661904

5. Anderson SG. Engaging Students in Community-Based Research: A Model for Teaching Social Work Research. Journal of Community Practice. 2002;10(2):71-87. doi:10.1300/J125v10n02_05

6. Clem JM, Mennicke AM, Beasley C. Development and Validation of the Experiential Learning Survey. Journal of Social Work Education. 2014;50(3):490-506. doi:10.1080/10437797.2014.917900

7. Jewell JR. Owens AP. Confronting carceral power through experiential learning in macro social work practice. Social Work Education. 2017;36(4):403-413. doi:10.1080/02615479.2017.1297785

8. Shera W, Muskat B, Delay D, Quinn A, Tufford L. Using a Group Work Practice Standards Inventory to Assess the Impact of a "Social Work Practice with Groups" Course. Social Work with Groups. 2013:36(2-3):174-190. doi:10.1080/01609513.2012.745110.

9. Warkentin B. Teaching Social Work with Groups: Integrating Didactic, Experiential and Reflective Learning. Social Work with Groups. 2017;40(3):233-243. doi:10.1080/01609513.2015.1124034.

10. Roberts AR, Sellers SL, Franks K, Nelson TS. Teaching Note-Social Work Week: Harnessing the Potential of Group Practice to Achieve Transformational Learning. Journal of Social Work Education. 2018;54(3):561-567. doi:10.1080/10437797.2018.1434431.

11. Pekrun R, Frenzel AC, Goetz T, Perry RP. The Control-Value Theory of Achievement Emotions: An Integrative Approach to Emotions in Education. 24. (n.d.).

12. Yusuf JE, Saitgalina M, Chapman DW. Work-life balance and well-being of graduate students. Journal of Public Affairs Education. 2020: 1-26. doi: 10.1080/15236803.2020.1771990.

13. Scott GW, Humphries S, Henri DC. Expectation, motivation, engagement and ownership: Using student reflections in the conative and affective domains to enhance residential field courses. Journal of Geography in Higher Education. 2019;43(3):280-298. doi:10.1080/03098265.2019.1608516

14. Amerman Goerdt L, Blaalid B, Elswick SE, Johnson DH, Delavega E, Kindle PA, Granruth LB. Teaching Characteristics and Student Satisfaction: Impact on Social Work Students' Interest in Policy. Journal of Social Work Education. 2019;55(4):767-776. doi:10.1080/10437797.2019.1611512

15. Schmidt C, Powell M, Alakaam A. Enhancing health professional student experiences with experiential 2020. learning. Retrieved from: https://www.researchgate.net/publication/344219822_Enhancing_health_professional_stude nt_experiences_with_experiential_learning.

16. Chorazy ML, Klinedinst KS. Learn by doing: A model for incorporating high-impact experiential learning into an undergraduate public health curriculum. Front Public Health. 2019;7(31). doi:10.3389/fpubh.2019.00031.

17. Al-Azawei A, Serenelli F, Lundqvist K. . Universal design for learning (UDL): A content analysis of peer reviewed journals from 2012-2015. Journal of the Scholarship of Teaching and Learning. 2016; 16(3):39-56. doi:10.14434/josotl.v16i3.19295. 
18. Artino AR Jr., Holmboe ES, Durning SJ. Control-value theory: Using achievement emotions to improve understanding of motivation, learning, and performance in medical education: AMEE Guide No. 64. Medical Teacher. 2012; 34(3): e148-e160. doi:10.3109/0142159X.2012.651515

19. Meyer DK, Turner JC. Scaffolding Emotions in Classrooms. In Emotion in Education. 2007:243-258. doi:10.1016/B978-012372545-5/50015-0

20. Mottet TP, Beebe SA. Proceedings from the 86th annual National Communication Association. Seattle, WA: ERIC. 2000.

21. Seethamraju R, Borman M. Influence of group formation choices on academic performance. Assessment \& Evaluation in Higher Education. 2009;34(1):31-40. doi:10.1080/02602930801895679

22. Council on Social Work Education. Specialized practice guide curricular guide for macro social work practice. 2018. Retrieved from: https://www.cswe.org/CMSPages/GetFile.aspx?guid=553d03b4-c1f5-4f23-8241a796edc6b922.

23. Rothman J. Education for macro intervention: A survey of problems and prospects (Doctoral dissertation, University of California, Los Angeles). 2012. Retrieved from: https://www.socialworkhelper.com/wp-content/uploads/2013/06/ACOSA+Reportby+Dr.+Rothman.pdf.

24. Maidment J, Brook G. Teaching and Learning Group Work Using Tutorial and Community Engagement. Social Work with Groups. 2014;37(1):73-84. doi:10.1080/01609513.2013.817066

\section{Statement of Contributions}

Andrea Silverman Morgan Friedman, Jalisa Whiting-Smalls, and Nadi Wisseh conducted background research, reviewed student quotes, and wrote all sections of the report. Laurie Friedman helped create the idea for this case report, reviewed student reflection papers for quotes, and provided guidance and input on all sections of the report. Jennifer Ibrahim provided input and support in editing this case report. 